\title{
Pengukuran Knowledge Management Readiness pada Perguruan Tinggi Cahaya Surya Kediri
}

\author{
Tutus Praningki ${ }^{1}$ \\ ${ }^{1}$ Sekolah Tinggi Teknologi Cahaya Surya Kediri \\ 1praningki@cahayasurya.ac.id
}

\begin{abstract}
Abstrak
Perguruan Tinggi Cahaya Surya Kediri merupakan lembaga penyedia jasa layanan pendidikan yang terdiri dari strata S1 dan D3. Pada proses peningkatan kualitas perguruan tinggi sering terkendala oleh intesitas keluar masuk atau turnover dosen dan tenaga kependidikan yang tergolong tinggi. Terjadinya turnover karyawan yang tinggi mengakibatkan proses penyesuaian karyawan baru menjadi lambat. Proses pengelolaan pengetahuan dan pengalaman sangat diperlukan untuk mengatasi permasalahan pada institusi Cahaya Surya Kediri. Implementasi pengelolaan pengetahuan atau sering disebut knowledge management membutuhkan kesiapan dan komitmen sebuah institusi, oleh karena itu dibutuhkan proses pengukuran yaitu knowledge management readiness. Proses pengukuran menggunakan metode pemetaan Knowledge Management Critical Success Factors (KMCSF). Hasil penelitian menunjukkan bahwa perguruan tinggi Cahaya Surya Kediri berada pada level tiga (3) atau siap untuk menerapkan knowledge management
\end{abstract}

Kata Kunci-Knowledge Management, Knowledge Management Readiness, Knowledge Management Critical Success Factors, turnover

\section{PENDAHULUAN}

Cahaya Surya Kediri merupakan perguruan tinggi swasta yang menyediakan program studi S1 Teknik Informatika, S1 Sastra Inggris, dan D3 Akuntansi. Program studi S1 Teknik Informatika dan D3 Akuntansi Cahaya Surya dibuka tahun 1996 dan merupakan pertama kali yang ada di kota Kediri. Bertambahnya waktu banyak perguruan tinggi lainya yang membuka program studi tersebut. Jika dibandingkan dengan para pesaingnya, hanya program studi D3 Akuntansi yang memiliki keunggulan, yaitu mempunyai akreditasi B. Hal tersebut tidak sejalan dengan perkembangan program studi S1 Teknik Informatika maupun S1 Sastra Inggris yang dapat dikatakan stagnan. Salah satu penyebabnya adalah itensitas keluar masuk (turnover) tenaga kependidikan dan dosen yang tinggi, banyak karyawan yang memiliki skill dan pengalaman memutuskan untuk keluar dari institusi, sehingga pegawai baru akan sulit menyesuaikan diri dengan pekerjaan yang baru karena ilmu dan kegiatan tidak terdokumentasi. Proses pembelajaran terhadap karyawan baru tersebut dapat mengakibatkan terhambatnya proses perkembangan institusi, baik dari segi sumber daya maupun motivasi karyawan lainya. Pada berbagai sisi perusahan atau organisasi turnover akan mengakibatkan kerugian [1], namun pada penelitian ini tidak membahas penyebab terjadinya turnover karyawan melainkan solusi yang diperlukan untuk mereduksi dampak dari turnover. 
Kondisi yang terjadi pada institusi Cahaya Surya Kediri sangat diperlukan penerapan Knowledge Management (KM), hal ini dikarenakan kemampuan KM dalam mengelola pengetahuan dan membagikan keseluruh pegawai sehingga organisasi dapat belajar dengan cepat terhadap perubahan yang terjadi dalam organisasi [2]. Proses utama KM adalah berbagi pengetahuan tacit secara efektif dan pengalihan pengetahuan eksplisit dalam meningkatkan kinerja organisasi dan inovasi [3], sehingga dengan implementasi KM dapat mengatasi permasalahan diatas dan mampu meningkatkan kinerja institusi Cahaya Surya Kediri. Penerapan KM dalam organisasi harus mempertimbangkan banyak hal, karena investasi pada proyek-proyek KM memerlukan banyak waktu dan biaya, sehingga investasi dalam KM harus dapat dipastikan keberhasilanya. Menurut [4] keberhasilan proyek KM sangat bergantung pada kesiapan organisasi tersebut untuk menerapkan.

Menurut Daniel Morehead yang merupakan direktur dari organisasi penelitian dibawah British Telecommunications PLC menyatakan bahwa tingkat kegagalan proyek KM sebesar 70\%. Kegagalan proyek KM banyak disebabkan penerapan sistem hanya berdasarkan teori saja tanpa mempertimbangkan keadaan organisasi [4]. Menyadari akan potensi kegagalan proyek KM, dan motivasi untuk keberhasilan proyek KM maka sangat diperlukan sebuah pengukuran terhadap kesiapan sebuah organisasi khususnya Cahaya Surya Kediri, sehingga dapat memastikan ketika KM diimplementasikan dapat memberikan manfaat bagi institusi Cahaya Surya Kediri. Melalui pengukuran kesiapan KM dapat membantu organisasi untuk menganalisis kesiapan untuk berbagi pengetahuan yang efektif sebelum sistem KM diimplementasikan [5].

\section{KNOWLEDGE MANAGEMENT}

Knowledge management adalah kegiatan untuk menemukan, menangkap, berbagi dan menerapkan pengetahuan dalam rangka untuk mencapai tujuan organisasi [3]. Sedangkan menurut [6] knowledge management merupakan proses mengidentifikasi, memilih, mengelola, mengirim dan menyebarkan informasi untuk memecahkan masalah perencanaan strategis, pengambilan keputusan dan peningkatan nilai modal intelektual. Knowledge management bertujuan untuk meningkatkan cara mendistribusikan data mentah kedalam bentuk informasi yang bermanfaat, sehingga menjadi pengetahuan dan dapat dimanfaatkan oleh seluruh elemen organisasi. Konsep knowledge menurut Nonaka dan Takeuchi (1995) ada 4 tahapan dalam mencipatkan knowledge yang sering disebut SECI, seperti gambar 1.

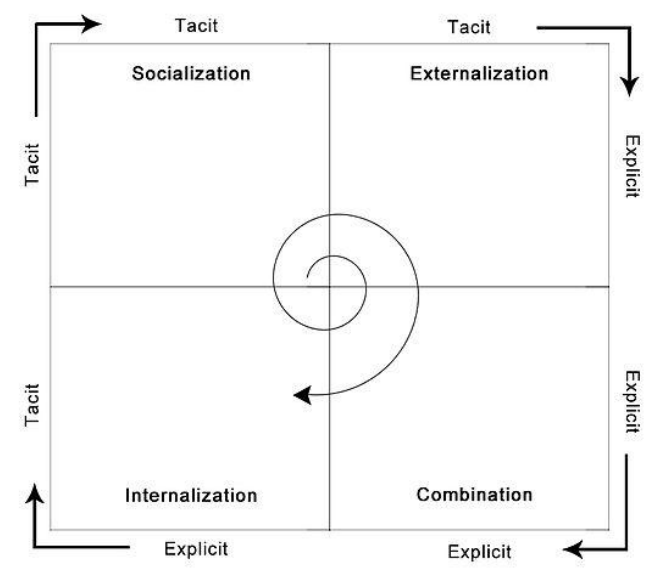

Gambar. 1 SECI model

Sumber : https://en.wikipedia.org/wiki/SECI model 
Implementasi knowledge management diperlukan sebuah knowledge management system (KMS), KMS menurut [7] merupakan teknologi yang memungkinkan knowledge management untuk berjalan dengan efektif dan efisien. Menurut [8] dalam melakukan pengukuran KM readiness dapat digunakan dari indikator Knowledge Management Critical Success Factors (KMCSF). Melalui penelitian oleh [9], [10] pemetaan indikator juga melibatkan aspek knowledge management dan KM infrastruktur.

\subsection{Knowledge Management Critical Success Factors (KMCSF)}

Menurut [11] penentu keberhasilan implementasi knowledge management dapat ditentukan 5 faktor utama, yaitu:

- Leadership

- Culture

- Structure, roles, and responsibilities

- Information Technology Infrastruktur

- Measurement

Sedangkan dalam penelitian oleh [12] didapatkan hasil bahwa faktor yang mempengaruhi KMCSF adalah

- Knowledge strategy

- Management support

- Dorongan motivasi untuk berbagi pengetahuan

- Infrastruktur teknis yang sesuai.

Menurut [13], ada 10 faktor yang mempengaruhi keberhasilan dalam menerapkan KM, yaitu:

- Kepemimpinan

- Budaya

- Proses

- Explicit knowledge

- Tacit knowledge

- Knowledge hubs and centers

- Pengukuran

- Eksploitasi pemasaran

- Keahlian pegawai

- Infrastruktur Teknologi

\subsection{Aspek Knowledge Management}

Menurut [14] aspek knowledge management terdiri dari 3 aspek yaitu aspek teknis (Hard), aspek organisasi (Soft), dan aspek Abstrak. Pada tabel 1, dapat dijelaskan bagaimana ketiga aspek tersebut dibedakan.

Tabel 1. Aspek Knowledge Management menurut Holt

\begin{tabular}{|l|l|l|}
\hline Teknis (Hard) & \multicolumn{1}{|c|}{$\begin{array}{c}\text { Organisasi } \\
\text { (Soft) }\end{array}$} & \multicolumn{1}{|c|}{ Abstract } \\
\hline $\begin{array}{l}\text { Aspek teknis } \\
\text { tools } \text { KM }\end{array}$ & $\begin{array}{l}\text { Pembelajaran } \\
\text { organisasi }\end{array}$ & Definisi dari \\
KM \\
\hline Evaluasi tools & Business & Filosofis dan \\
KM & intelligence & $\begin{array}{l}\text { psikologis } \\
\text { aspek-aspek }\end{array}$ \\
& & KM dari \\
& & pengetahuan \\
\hline
\end{tabular}




\begin{tabular}{|l|l|l|}
\hline Teknis (Hard) & \multicolumn{1}{|c|}{$\begin{array}{c}\text { Organisasi } \\
\text { (Soft) }\end{array}$} & \multicolumn{1}{|c|}{ Abstract } \\
\hline $\begin{array}{l}\text { Metodologi } \\
\text { pemilihan } \\
\text { tools KM }\end{array}$ & $\begin{array}{l}\text { Aspek budaya } \\
\text { dari KM }\end{array}$ & $\begin{array}{l}\text { Taksonomi } \\
\text { dari KM }\end{array}$ \\
\hline $\begin{array}{l}\text { Kebutuhan } \\
\text { untuk } \\
\text { pengembangan } \\
\text { tools KM }\end{array}$ & $\begin{array}{l}\text { Struktur } \\
\text { organisasi yang } \\
\text { mendukung } \\
\text { KM }\end{array}$ & $\begin{array}{l}\text { Epistemologi } \\
\text { dan ontologi } \\
\text { dari KM }\end{array}$ \\
\hline $\begin{array}{l}\text { Proses dan } \\
\text { tools untuk } \\
\text { pengenalan } \\
\text { pengetahuan }\end{array}$ & $\begin{array}{l}\text { Best practice in } \\
\text { KM }\end{array}$ & $\begin{array}{l}\text { Metode yang } \\
\text { tepat untuk } \\
\text { menyelidiki } \\
\text { fenomena KM }\end{array}$ \\
\hline $\begin{array}{l}\text { Survei tools } \\
\text { KM }\end{array}$ & $\begin{array}{l}\text { Manajemen } \\
\text { sumberdaya } \\
\text { dalam konteks } \\
\text { KM }\end{array}$ & $\begin{array}{l}\text { Manajemen } \\
\text { proyek dalam } \\
\text { konteks KM }\end{array}$ \\
\hline $\begin{array}{l}\text { Multi-agent } \\
\text { technology for } \\
\text { knowledge } \\
\text { discovery }\end{array}$ & $\begin{array}{l}\text { Manajemen } \\
\text { operasional } \\
\text { dalam konteks } \\
\text { KM }\end{array}$ & \\
\hline
\end{tabular}

\subsection{Knowledge Management Infrastruktur}

Menurut [3] KM infrastruktur terdiri dari 5 komponen, yaitu :

- Budaya organisasi

- Struktur organisasi

- Infrastruktur Teknologi Informasi

- Pengetahuan umum

- Lingkungan Fisik

KM infrastruktur merupakan bagian dari KM foundation, dan merupakan dasar dari KM foundation serta KM solution. Posisi KM infrastruktur dapat dijelaskan pada gambar 2 dibawah ini.

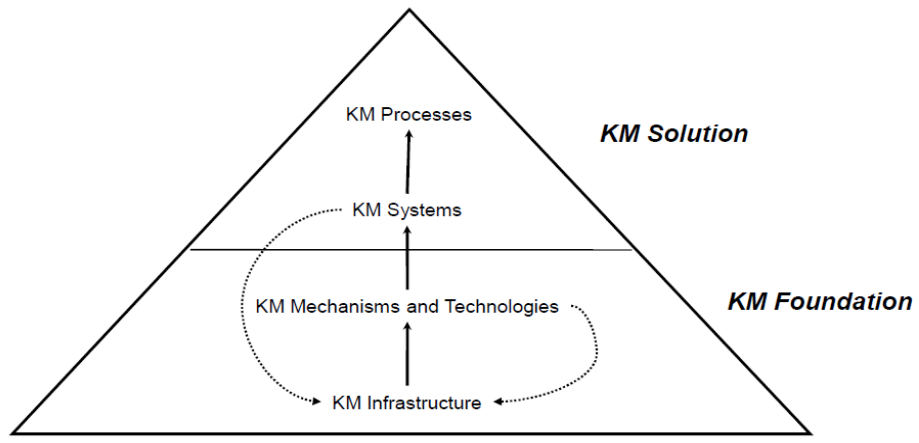

Gambar 2. Model KM foundation dan KM solution Sumber : Becerra-Fernandez (2004) 
Pada gambar 2 dapat dijelaskan bahwa KM infrastruktur merupakan elemen penting dalam implementasi knowledge management.

\subsection{Knowledge Management Readiness}

Menurut [14] KM readiness adalah kemampuan suatu organisasi, departemen atau kelompok kerja untuk berhasil untuk mengadopsi, menggunakan, dan memanfaatkan KM. Sangat penting sebuah organisasi mengetahui tingkat kesiapan mereka sebelum mengimplementasikan KM, dengan pengkuran dapat membantu organisasi dalam pengambilan keputusan berkaitan dengan hasil tersebut [5]. Klasifikasi tingkat kesiapan dapat dibagi menjadi 5 level [9], yaitu:
a. Tidak siap
b. Awal
c. Siap
d. Reseptif
e. Optimal

Seperti [15], tingkat kesiapan dapat dibagi kedalam bentuk persentase, seperti gambar 3 dibawah ini.

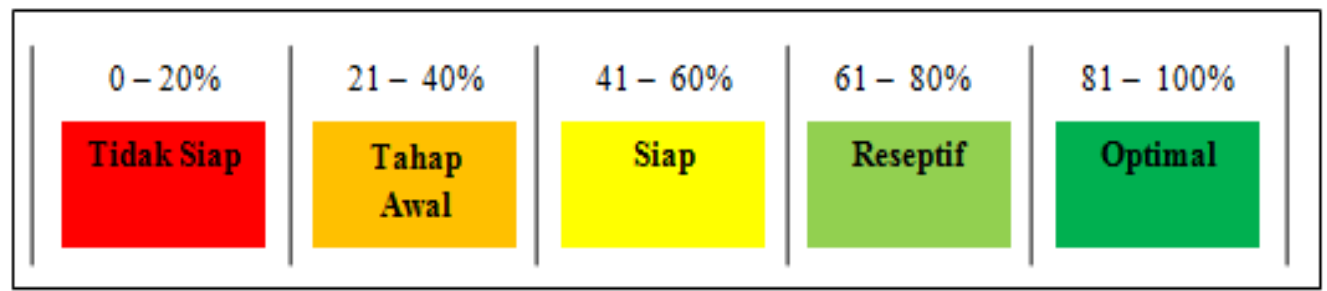

Gambar 3. Level KM readiness

Pada penelitian oleh [9] untuk mendapatkan nilai persentase level digunakan rumus:

$$
\mathrm{P}=\mathrm{Sn} / \mathrm{Sm} \times 100 \%
$$

Keterangan:

$\mathrm{P}=$ Presentase level

$\mathrm{Sn}=$ Jumlah skor $\mathrm{x}$ bobot yang didapatkan

$\mathrm{Sm}=$ Total skor $\mathrm{x}$ bobot maksimal

\section{METODE PENELITIAN}

\subsection{Penentuan Sampel}

Pemilihan sampel menggunakan metode purposive sampling, karena kriteria yang diambil adalah sudah bekerja selama lebih dari 1 bulan, bekerja pada bagian staf BAAK, BAU, IT, dan dosen tetap. Kriteria tersebut didapatkan sampel sebanyak 34 karyawan. Mengacu pada pendapat [16] bahwa apabila dalam pengambilan sampel subyeknya kurang dari 100, maka harus diambil semua.

\subsection{Pengumpulan Data}

Pada tahap ini dilakukan pembuatan kuesioner, kuesioner dirancang dan mengadopsi dari penelitian [9], [10]. Jumlah pertanyaan pada kuesioner adalah 38 butir pertanyaan yang terbagi kedalam aspek Abstract 6 pertanyaan, Soft 25 pertanyaan, dan Hard 7 pertanyaan, dengan skor penilaian sebagai berikut:

- Sangat Tidak Setuju $\rightarrow$ Skor 1

- Tidak Setuju $\rightarrow$ Skor 2 
- Setuju $\rightarrow$ Skor 3

- Sangat Setuju $\rightarrow$ Skor 4

- Sangat Setuju Sekali $\rightarrow$ Skor 5

Data yang dikumpulkan berhasal dari kuesioner yang dibagikan kepada responden dan dari hasil jawaban dari setiap responden akan dilakukan uji reliabilitas dan validitas.

\subsection{Uji Validitas dan Reliabilitas}

Uji validitas digunakan untuk mengukur item pertanyaan, sehingga diketahui apakah item tersebut benar bisa digunakan untuk mengukur suatu penelitian [17]. Teknik yang digunakan untuk mengetahui validitas adalah jika $r_{\text {hitung }}>r_{\text {tabel }}$ dengan jumlah responden 34. Derajat kebebasan yang digunakan adalah N-2 dan nilai signifikansi 5\% (0.05). Dari rtabel untuk df $=(\mathrm{N}-2)=34-2=32$ adalah 0.3388. Pada uji reliabilitas digunakan rumus Cronbach's Alpha [18], tujuanya adalah untuk mengevaluasi dari keandalan data.

$$
\mathrm{r}_{11}=\llbracket \frac{\mathrm{k}}{\mathrm{k}-1} \rrbracket \llbracket 1-\frac{\sum \sigma_{\mathrm{b}}^{\mathrm{a}}}{\sigma_{\mathrm{t}}^{2}} \rrbracket
$$

\subsection{Pengukuran KM Readiness}

Pengukuran dilakukan dengan menggunakan metode seperti pada penelitian oleh [9], [10], pengukuran dilakukan terlebih dahulu untuk presentase level setiap variabel. Langkah berikutnya dari hasil pengukuran tiap variabel akan dilakukan penghitungan presentase level pada 3 aspek knowledge management, yaitu Abstract, Soft, dan Hard.

\section{HASIL DAN PEMBAHASAN}

\subsection{Rancangan Instrumen}

Hasil penelitian ini terdiri rancangan instrumen berdasarkan pemetaan terhadap $\mathrm{KMCSF}$, aspek knowledge management, dan infrastruktur KM, gambaran dari rancangan instrumen tersebut dapat dilihat pada gambar 4.

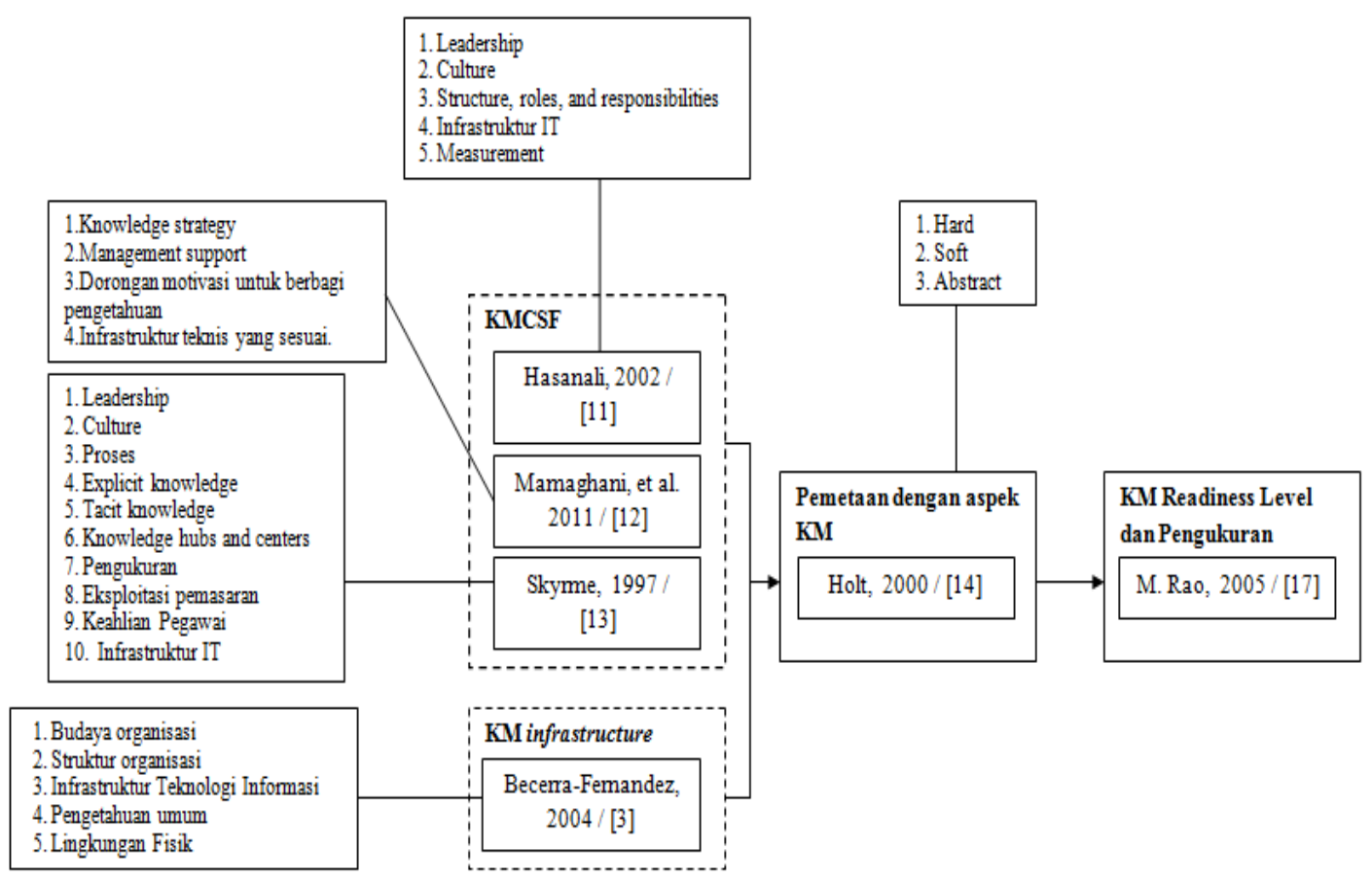

Gambar 4. Rancangan instrumen 

ini.

Pada rancangan instrumen seperti gambar 4, didapatkan hasil pada tabel 2 dibawah

Tabel 2. Hasil Pemetaan KM Readiness

\begin{tabular}{|c|c|c|c|c|}
\hline Aspek & $\begin{array}{c}\text { KMCSF } \\
\text { (Hasanali) }\end{array}$ & $\begin{array}{c}\text { KMCSF } \\
\text { (Mamaghani) }\end{array}$ & $\begin{array}{c}\text { KMCSF } \\
\text { (Skyrme) }\end{array}$ & $\begin{array}{c}\text { Infrastruktur } \\
\text { KM }\end{array}$ \\
\hline Abstract & & & & \\
\hline \multirow{8}{*}{ Soft } & Leadership & $\begin{array}{l}\text { Management } \\
\text { support }\end{array}$ & Leadership & $\begin{array}{l}\text { Budaya } \\
\text { Organisasi }\end{array}$ \\
\hline & Culture & $\begin{array}{l}\text { Knowledge } \\
\text { Strategy }\end{array}$ & Culture & $\begin{array}{l}\text { Strutur } \\
\text { Organisasi } \\
\end{array}$ \\
\hline & $\begin{array}{l}\text { Structure, } \\
\text { roles, and } \\
\text { responsibilities }\end{array}$ & $\begin{array}{l}\text { Dorongan } \\
\text { motivasi } \\
\text { untuk berbagi } \\
\text { pengetahuan }\end{array}$ & Proses & $\begin{array}{l}\text { Pengetahuan } \\
\text { umum }\end{array}$ \\
\hline & Measurement & & $\begin{array}{l}\text { Explicit } \\
\text { knowledge }\end{array}$ & \\
\hline & & & $\begin{array}{l}\text { Tacit } \\
\text { knowledge }\end{array}$ & \\
\hline & & & Measurement & \\
\hline & & & $\begin{array}{l}\text { Exploitasi } \\
\text { pemasaran }\end{array}$ & \\
\hline & & & $\begin{array}{l}\text { Keahlian } \\
\text { Pegawai }\end{array}$ & \\
\hline \multirow[t]{2}{*}{ Hard } & $\begin{array}{l}\text { Infrastruktur } \\
\text { IT }\end{array}$ & $\begin{array}{l}\text { Infrastruktur } \\
\text { teknik yang } \\
\text { sesuai }\end{array}$ & $\begin{array}{l}\text { Knowledge } \\
\text { hubs and } \\
\text { centers }\end{array}$ & Infrastruktur IT \\
\hline & & & $\begin{array}{l}\text { Infrastruktur } \\
\text { Teknologi }\end{array}$ & $\begin{array}{l}\text { Lingkungan } \\
\text { Fisik }\end{array}$ \\
\hline
\end{tabular}

Pada tabel 3 dapat diketahui bahwa belum terdapat variabel yang dapat dimasukkan kedalam aspek abstract, oleh karena itu akan digunakan variabel hasil pemetaan pada [9]. Pada [9] terdapat 2 variabel yang terdapat pada aspek Abstract, yaitu:

a. Pemahaman mengenai definisi dan manfaat KM.

b. Inisiatif organisasi dalam menerapkan KM.

Melalui pemetaan instrumen diatas dapat dirumuskan varibel pengukuran yang sama seperti pada [10].

Tabel 3. Variabel Pengukuran

\begin{tabular}{|l|l|}
\hline Aspek & \multicolumn{1}{|c|}{ Variabel Pengukuran } \\
\hline \multirow{3}{*}{ Abstract } & Pemahaman dan manfaat KM \\
\cline { 2 - 2 } & Inisiatif penerapan KM \\
\hline \multirow{5}{*}{ Soft } & Budaya \\
\cline { 2 - 2 } & $\begin{array}{l}\text { Dukungan manajemen / } \\
\text { kepemimpinan }\end{array}$ \\
\cline { 2 - 2 } & Sumber Daya Manusia \\
\cline { 2 - 2 } & Proses \\
\cline { 2 - 2 } & Pengukuran \\
\hline
\end{tabular}




\begin{tabular}{|l|l|}
\hline \multirow{2}{*}{ Hard } & Variabel Pengukuran \\
\cline { 2 - 2 } & Learning / Pembelajaran \\
\cline { 2 - 2 } & Struktur organisasi dan strategi \\
\hline \multirow{2}{*}{} & Infrastruktur TI \\
\cline { 2 - 2 } & Lingkungan fisik \\
\hline
\end{tabular}

\subsection{Uji Validitas}

Hasil dari uji validitas terhadap intrumen pertanyaan dengan menggunakan software SPSS v.16, didapatkan hasil seperti tabel 4.

Tabel 4. Hasil Uji Validitas

\begin{tabular}{|l|l|l|c|c|}
\hline No & Hasil & No. Pertanyaan & Jumlah & Persentase \\
\hline 1 & Valid & A1, A2, A3, A4, A5, & 33 & $87 \%$ \\
& & A6, S7, S8, S9, S10, & & \\
& & S11, S12, S14, S16, & & \\
& & S17, S18, S19, S21, & & \\
& & S22, S23, S24, S25, & & \\
& & S26, S27, S28, S30, & & \\
& & S31, H32, H34,H35, & & \\
\hline 2 & Tidak Valid & S13, S15, S20, S29, H33 & 5 & $13 \%$ \\
\hline & & Total & 38 & $100 \%$ \\
\hline
\end{tabular}

Berdasarkan tabel 4, sebanyak $33(87 \%)$ item pertanyaan dinyatakan valid dan 5 item pertanyaan tidak valid, sehingga item pertanyaan yang memenuhi syarat untuk dijadikan instrumen penelitian adalah 33 item, sebab menurut [19] instrumen yang valid berarti instrumen tersebut dapat mengukur terhadap sesuatu yang diukur.

\subsection{Uji Reliabilitas}

Hasil dari uji reliabilitas dengan software SPSS didapatkan hasil seperti gambar 5 dibawah ini.

\begin{tabular}{|ll|r|r|}
\multicolumn{4}{c}{ Case Processing Summary } \\
\hline & \multicolumn{1}{c|}{$N$} & \multicolumn{1}{c|}{$\%$} \\
\hline Cases & Valid & 34 & 100.0 \\
& Excluded & 0 & .0 \\
& Total & 34 & 100.0 \\
\hline
\end{tabular}

a. Listwise deletion based on all variables in the procedure.

\begin{tabular}{|c|c|c|}
\hline \multicolumn{3}{|c|}{ Reliability Statistics } \\
\hline $\begin{array}{c}\text { Cronbach's } \\
\text { Alpha }\end{array}$ & $\begin{array}{c}\text { Cronbach's } \\
\text { Alpha Based } \\
\text { on } \\
\text { Standardized } \\
\text { Items } \\
\end{array}$ & Nof ltems \\
\hline .901 & .904 & 38 \\
\hline
\end{tabular}

Gambar 5. Hasil Uji Reliabilitas 
Hasil diatas didapatkan nilai Cronbach's Alpa sebesar 0,901, jika nilai rtabel dari N $=34$ dengan signifikan 5\% adalah 0,339, maka dapat dinyatakan item - item tersebut sangat signifikan karena $0,901>$ rtabel $(0,339)$. Tingkat signifikan dapat dijelaskan melalui tabel 5.

Tabel 5. Tingkat Reliabel Menurut Sugiyono

\begin{tabular}{|l|l|}
\hline Cronbach's Alpa & \multicolumn{1}{|c|}{ Tingkat Reliabilitas } \\
\hline $0,00-0,19$ & Sangat kurang reliabel \\
\hline $0,2-0,39$ & Kurang reliabel \\
\hline $0,4-0,59$ & Agak reliabel \\
\hline $0,6-0,79$ & Reliabel \\
\hline $0,8-1$ & Sangat Reliabel \\
\hline
\end{tabular}

\subsection{Hasil Pengkuran Aspek KM}

Pengukuran aspek Abstract, Soft, dan Hard melalui hasil kuesioner yang dibagiakan kepada responden, didapatkan hasil untuk aspek abstract seperti tabel 6.

Tabel 6. Hasil Aspek Abstrak

\begin{tabular}{|c|c|c|c|c|c|c|}
\hline Item & \multicolumn{7}{|c|}{ Jumlah Bobot } & $\begin{array}{c}\text { (N) / } \\
\text { Responden }\end{array}$ \\
\hline & $\boldsymbol{1}$ & $\mathbf{2}$ & $\mathbf{3}$ & $\mathbf{4}$ & $\mathbf{5}$ & \\
\hline A1 & 0 & 2 & 17 & 12 & 3 & 34 \\
\hline A2 & 0 & 0 & 20 & 14 & 0 & 34 \\
\hline A3 & 0 & 16 & 17 & 1 & 0 & 34 \\
\hline A4 & 0 & 0 & 10 & 20 & 4 & 34 \\
\hline A5 & 0 & 0 & 9 & 18 & 7 & 34 \\
\hline A6 & 0 & 1 & 11 & 21 & 1 & 34 \\
\hline Jumlah & 0 & 19 & 84 & 86 & 15 & 204 \\
\hline Jumlah Bobot & 0 & 38 & 252 & 344 & 75 & 1020 \\
\hline Bobot Total & \multicolumn{7}{|c|}{709} \\
\hline Presentase Level & $709 / 1020) * 100=\mathbf{6 9 , 5 1 \%}$ \\
\hline
\end{tabular}

Tabel diatas didapatkan bahwa untuk aspek absract presentase level KM readiness adalah $69,51 \%$ dan dapat diartikan berada pada posisi reseptif. Pada pengukuran untuk aspek soft, didapatkan hasil pada tabel 7 dibawah ini.

Tabel 7. Hasil Aspek Soft

\begin{tabular}{|c|c|c|c|c|c|c|}
\hline Item & \multicolumn{7}{|c|}{ Jumlah Bobot } & $\begin{array}{c}(\boldsymbol{N}) / \\
\text { Responden }\end{array}$ \\
\hline & $\mathbf{1}$ & $\mathbf{2}$ & $\mathbf{3}$ & $\mathbf{4}$ & $\mathbf{5}$ & \\
\hline S7 & 0 & 1 & 5 & 26 & 2 & 34 \\
\hline S8 & 0 & 0 & 13 & 19 & 2 & 34 \\
\hline S9 & 0 & 2 & 21 & 11 & 0 & 34 \\
\hline S10 & 0 & 1 & 13 & 18 & 2 & 34 \\
\hline S11 & 0 & 0 & 15 & 18 & 1 & 34 \\
\hline S12 & 0 & 12 & 18 & 2 & 2 & 34 \\
\hline S14 & 0 & 0 & 14 & 18 & 2 & 34 \\
\hline
\end{tabular}




\begin{tabular}{|c|c|c|c|c|c|c|}
\hline \multirow[t]{2}{*}{ Item } & \multicolumn{5}{|c|}{ Jumlah Bobot } & \multirow{2}{*}{$\begin{array}{c}(N) / \\
\text { Responden }\end{array}$} \\
\hline & 1 & 2 & 3 & 4 & 5 & \\
\hline S16 & 2 & 18 & 14 & 0 & 0 & 34 \\
\hline S17 & 2 & 21 & 11 & 0 & 0 & 34 \\
\hline S18 & 0 & 5 & 19 & 10 & 0 & 34 \\
\hline S19 & 0 & 1 & 17 & 15 & 1 & 34 \\
\hline S21 & 1 & 8 & 17 & 6 & 2 & 34 \\
\hline S22 & 2 & 16 & 7 & 7 & 2 & 34 \\
\hline S23 & 2 & 10 & 17 & 4 & 1 & 34 \\
\hline S24 & 0 & 9 & 22 & 3 & 0 & 34 \\
\hline S25 & 0 & 0 & 20 & 13 & 1 & 34 \\
\hline S26 & 0 & 3 & 18 & 12 & 1 & 34 \\
\hline S27 & 2 & 12 & 16 & 4 & 0 & 34 \\
\hline S28 & 0 & 9 & 16 & 9 & 0 & 34 \\
\hline $\mathrm{S} 30$ & 0 & 9 & 13 & 10 & 2 & 34 \\
\hline S31 & 0 & 2 & 16 & 15 & 1 & 34 \\
\hline Jumlah & 11 & 139 & 322 & 217 & 22 & 714 \\
\hline Jumlah Bobot & 11 & 278 & 966 & 868 & 110 & 3570 \\
\hline Bobot Total & & & 223 & & & 3570 \\
\hline Presentase Level & & & $3 / 3$ & 0) * & $0=6$ &, $50 \%$ \\
\hline
\end{tabular}

Tabel 7 didapatkan bahwa untuk aspek soft presentase level KM readiness adalah $62,50 \%$ dan dapat diartikan berada pada posisi reseptif. Sedangkan hasil pengukuran pada aspek hard dapat dilihat pada tabel 8.

Tabel 8. Hasil Aspek Hard

\begin{tabular}{|c|c|c|c|c|c|c|}
\hline Item & \multicolumn{7}{|c|}{ Jumlah Bobot } & $\begin{array}{c}\text { (N) / } \\
\text { Responden }\end{array}$ \\
\hline & $\mathbf{1}$ & $\mathbf{2}$ & $\mathbf{3}$ & $\mathbf{4}$ & $\mathbf{5}$ & \\
\hline H32 & 0 & 10 & 20 & 4 & 0 & 34 \\
\hline H34 & 3 & 17 & 14 & 0 & 0 & 34 \\
\hline H35 & 0 & 11 & 20 & 3 & 0 & 34 \\
\hline H36 & 2 & 14 & 17 & 1 & 0 & 34 \\
\hline H37 & 2 & 20 & 12 & 0 & 0 & 34 \\
\hline H38 & 2 & 21 & 11 & 0 & 0 & 34 \\
\hline Jumlah & 9 & 93 & 94 & 8 & 0 & 204 \\
\hline Jumlah Bobot & 9 & 186 & 282 & 32 & 0 & 1020 \\
\hline Bobot Total & \multicolumn{7}{|c|}{509} \\
\hline Presentase Level & \multicolumn{7}{|c|}{ (509/1020) * 100 = 49\% } \\
\hline
\end{tabular}

Hasil yang terdapat pada tabel 8 menunjukkan level kesiapan pada aspek hard adalah siap dengan nilai $49 \%$.

\subsection{Analisis Hasil}

Pada variabel pemahaman \& manfaat KM serta Inisiatif penerapan KM yang yang merupakan aspek abstract, berada pada level reseptif, seperti pada gambar grafik 6 . Pada kedua variabel tersebut tidak mempunyai selisih yang signifikan dan sama-sama berada pada level reseptif dengan rata-rata $69,51 \%$. Dengan berada pada level reseptif 
dapat diartikan bahwa adanya pemahaman yang kuat terhadap definisi dan manfaat KM, serta terdapat inisiatif dari Cahaya Surya Kediri dalam menerapkan KM.

\section{Aspek Abstract}

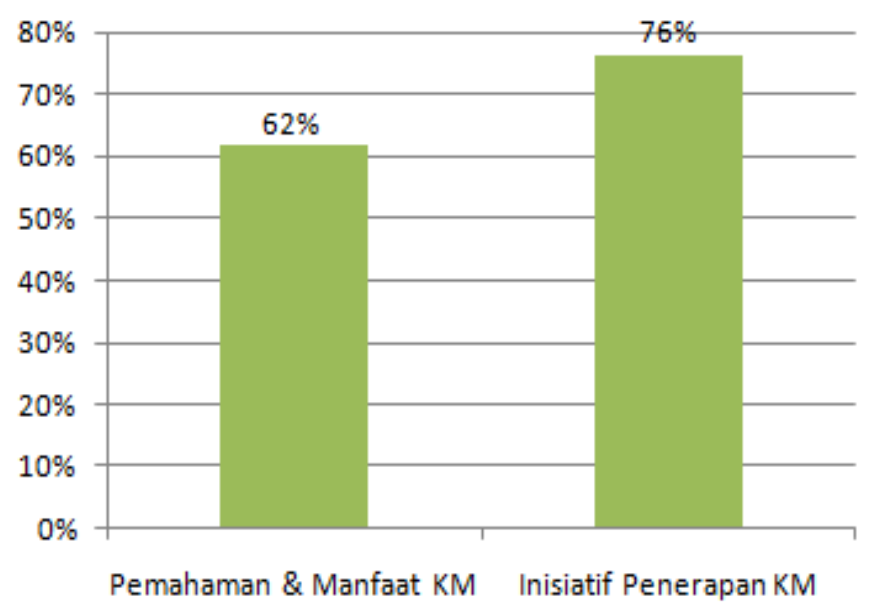

Gambar 6. Grafik nilai level kesiapan aspek abstract

Pada variabel-variabel yang termasuk dalam kategori aspek soft, terdapat 5 variabel berada pada level reseptif yaitu budaya \& organisasi 72\%, proses 65\%, SDM 64\%, strategi \& struktur organisasi $61 \%$, dan learning $70 \%$, sedangkan variabel pengukuran dan dukungan manajemen berada pada level siap. Rata-rata level kesiapan pada aspek soft adalah $62,5 \%$, sehingga setiap individu dan organisasi mendukung secara penuh terhadap implementasi KM dan rata-rata indikator dalam aspek soft telah dilakukan.

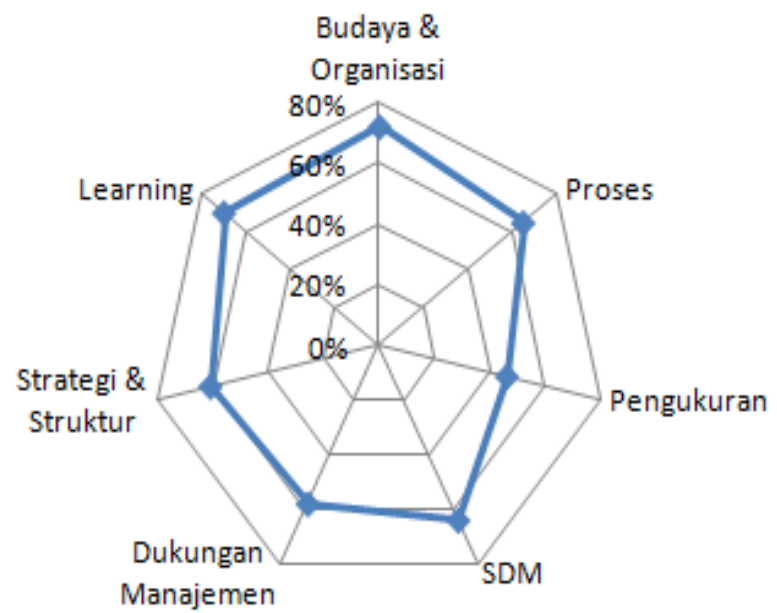

Gambar 7. Tingkat kesiapan aspek soft

Pada gambar 7 dapat dilihat pada variabel pengukuran berada pada level paling rendah diantara 7 variabel lain, hal ini mengindikasikan bahwa perlu ada perbaikan terhadap proses pengukuran terhadap aset KM. Pengukuran juga perlu ditingkatkan berkaitan dengan tingkat kopetensi dan sharing informasi. Harus ada komitmen dari seluruh anggota maupun pihak manajemen untuk melakukan pengukuran secara berkala, sehingga diketahui aset pengetahuan apa saja yang dimiliki oleh pihak Cahaya Surya Kediri. 
Analisis hasil dari pengukuran kesiapan implementasi KM selanjutnya adalah aspek Hard yang meliputi teknologi informasi dan lingkungan fisik. Pada gambar 8 menunjukkan bahwa kedua variabel sudah berada pada level siap, namun untuk variabel lingkungam diperlukan perbaikan dan hal ini sesuai dengan kondisi yang ada, dimana Cahaya Surya Kediri masih memiliki kendala berkaitan dengan keterbatasan ruangan.

Aspek Hard

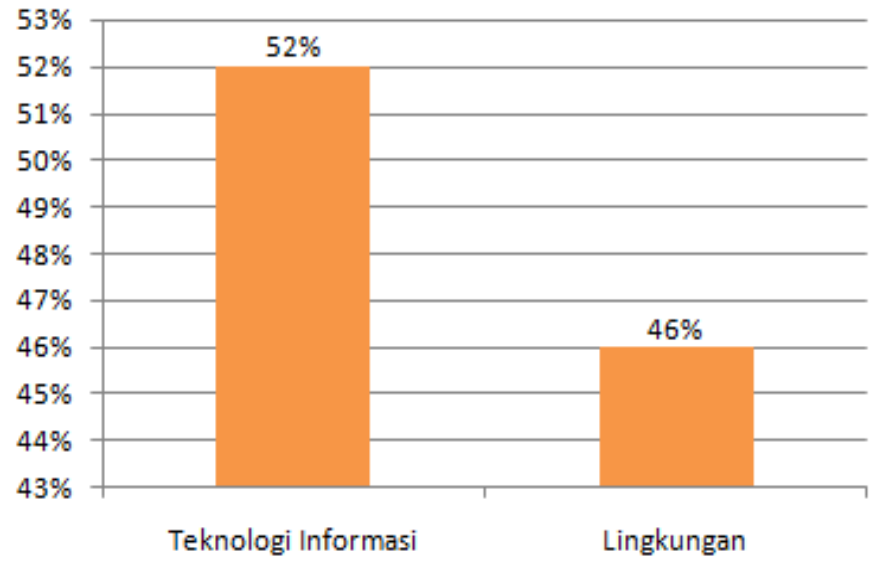

Gambar 8. Tingkat kesiapan aspek hard

Melalui perbandingan hasil dari ketiga aspek maka aspek abstract mempunyai nilai kesiapan tertinggi, dan masih berada pada level yang sama dengan aspek soft, yaitu berada pada level reseptif. Pada gambar 9 menunjukkan bahwa aspek hard memiliki nilai kesiapan paling rendah, sehingga perlu ada perbaikan agar berada pada level yang sama dengan kedua aspek lainya. Perbaikan yang perlu dilakukan adalah penyediaan infrastruktur yang baik, agar dapat mendukung teknologi informasi maupun lingkungan fisik, karena aspek hard merupakan elemen penting dari KM infrastruktur dan bagian dari KM foundation [3]. Mengacu pada 5 komponen KM infrastruktur yang diwakili melalui variabel budaya dan organisasi, struktur organisasi, Learning, Teknologi Informasi, dan lingkungan fisik, didapatkan rata-rata nilai kesiapan 60\%, sehingga berada pada level siap. Nilai perbedaan pada masing-masing variabel dapat dilihat pada gambar 10.

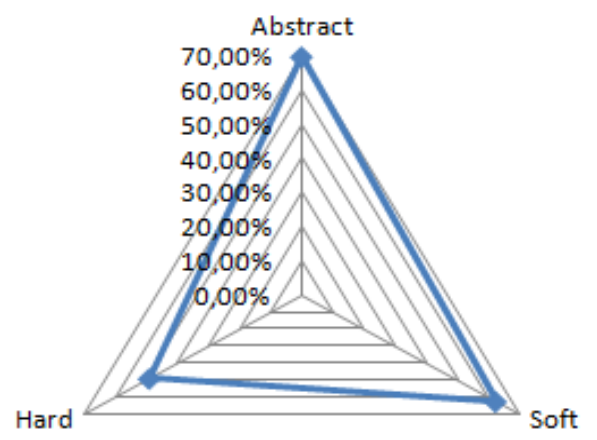

Gambar 9. Perbandingan tingkat kesiapan aspek abstract, soft, dan hard 


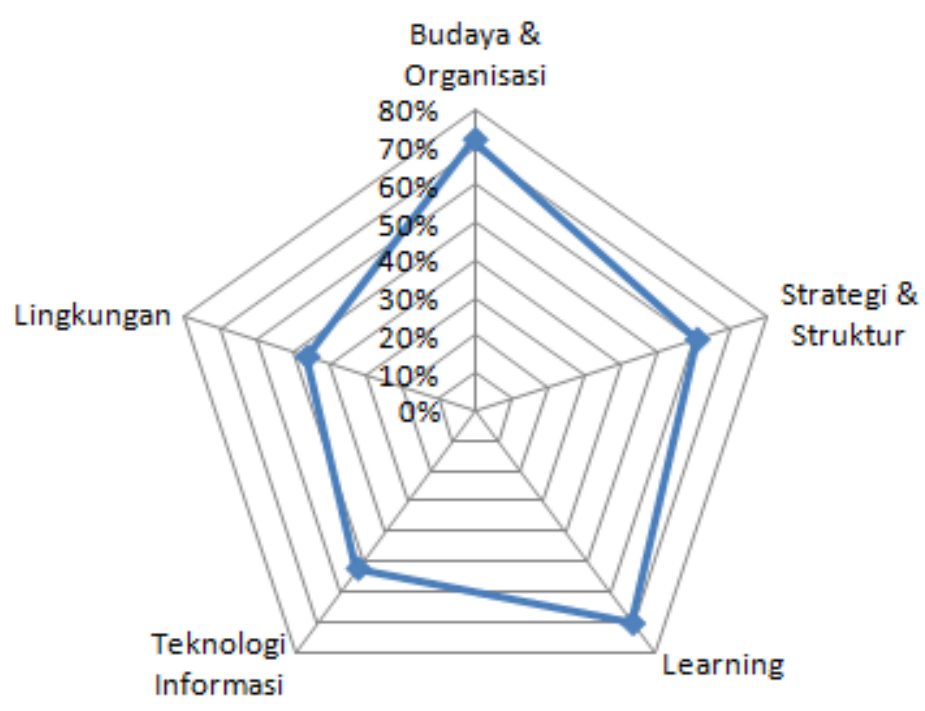

Gambar 10. Perbandingan tingkat kesiapan KM Infrastruktur

\section{KESIMPULAN}

Hasil dan analisa diatas dapat disimpulkan bahwa dalam ketiga aspek baik abstract, soft dan hard, berada pada level dimana knowledge management dapat diimplementasikan, dengan nilai presentase rata-rata sebesar $60 \%$. Terdapat hal yang harus menjadi bahan pertimbangan yang berkaitan dengan aspek hard, karena hasil dari pengukuran kesiapan knowledge management, level hard memiliki nilai terendah dibandingkan 2 aspek lainya. Hasil dari pengukuran pada KM infrastruktur, lingkungan fisik dan teknologi informasi juga mempunyai nilai presentase kesiapan terendah. Hasil yang didapatkan pada aspek hard mencerminkan kondisi yang ada pada Cahaya Surya Kediri, dimana kondisi saat ini masih belum memiliki ruangan khusus untuk proses KM. Teknologi informasi yang digunakan di Cahaya Surya Kediri juga tergolong terbatas, teknologi informasi yang dimanfaatkan saat ini untuk berbagi informasi adalah internet, email, video, dll, tidak terdapat software aplikasi yang khusus menangani proses KM, sehingga untuk memperbaiki aspek hard diperlukan investasi berupa teknologi informasi serta sarana dan prasarana yang mendukung proses KM.

Melalui metode Knowledge Management Critical Success Factors (KMCSF) serta KM Infrastruktur dapat digunakan sebagai indikator $\mathrm{KM}$ readiness, hal yang sama ditunjukkan oleh [9] [10].

\section{DAFTAR PUSTAKA}

[1] Cohen, A., 1999, Turnover among professionals: a longitudional study of american lawyers. Spring. Human Resources Management, vol. 38 , no. 1, pp. 6175.

[2] Gaziri, H., Awad, E., 2005, Is there a future for knowledge management. Jurnal of Information Technology Management, vol.16, no.1.

[3] Becerra-Fernandez, I., Gonzalez, A., Sabherwal, R., 2004, Knowledge Management -Challenges Solutions and Technologies.New Jersey, USA : Pearson Prentice Hal.

[4] Atrinawati, L. H., Surendro, K., 2009, Assessment for Knowledge Management Readiness. International Conference on Electrical Engineering and Informatics IEEE. 
[5] Keith, M., Goul, M., Demirkan, H., Nichols, J., 2006, Contextualizing Knowledge Management Readiness to Support Change Management Strategies. Proceedings of the 39th Hawaii International Conference on System Science, IEEE.

[6] Turban, J. E., Aronson, T., Liang, P., 2005, Decision Support System, 7th Edition. Pearson/Prentice Hall.

[7] Maier, R., Hädrich, T., 2006, Centralized versus peer-to-peer knowledge management systems. Knowledge and Process Management, vol. 13, pp. 47-61. 2006.

[8] Tiwana, A., 2001, The essential guide to knowledge management: E-bussines and CRM applications, Prentice Hall PTR.

[9] Perdana, A., A., 2014, Analsisi tingkat kesiapan implementasi knowledge management di pusat sistem informasi dan teknologi keuangan Kementrian Keuangan, Karya Akhir Program Magister Teknik Informasi Universitas Indonesia.

http://lib.ui.ac.id/file?file=digital/20367365-TA-

Airlangga\%20Agung\%20Perdana.pdf).

[10] Kuddah, F. A., 2014, "Analisis tingkat kesiapan implementasi knowledge management pada direktorat informasi kepabeanan dan cukai pada DJBC", Karya Akhir Program Magister Teknik Informasi Universitas Indonesia. http://lib.ui.ac.id/file?file=digital/2015-11/20390448-TA-

Faris\%20Achmad\%20Kuddah.pdf

[11] Hasanali, F., 2002, Critical success factors of knowledge management, APQC.

[12] Mamaghani, D., Samizadeh, R., Saghafi, F., 2011, Evaluating the readiness of Iranian research centers in knowledge management, 2011, American Journal of Economics and Business Administration, vol. 3, (1), pp.203-212.

[13] Skyrme, D., Amidon, D., 1997, The knowledge agenda, Jurnal of Knowledge Management, MCB UP Ltd, vol. 1(1), pp.27-37.

[14] Holt, D. T., 2000, The measurement of readiness for instrument and suggestions for future research, Academy of Management, Toronto, Canada.

[15] Rao, M., 2005, Knowledge management tools and techniques: practitioners and expert and evaluate KM solutions. Elsevier Butterworth-Heinemann.

[16] Arikunto, S., 2014, Prosedur penelitian: suatu pendekatan praktek, Bandung: Rineka Cipta.

[17] Purwanto, 2009, Evaluasi Hasil Belajar. Yogyakarta: Pustaka Pelajar.

[18] Tavakol, M., Dennick, R., 2011, Making sense of Cronbach's alpha, International Journal of Medical Education, vol. 2, pp. 53-55.

[19] Sugiyono, 2011, Metode Penelitian Kuantitatif, kualitatif, dan R \& D, hlm. 121. 